\title{
Characterization of dissolved organic matter fractions and its relationship with the disinfection by-product formation
}

\author{
ZHANG Hua $^{1,2}$, QU Jiuhui1 ${ }^{1, *}$, LIU Huijuan ${ }^{1}$, WEI Dongbin ${ }^{1}$ \\ 1. Research Center for Eco-Environmental Sciences, Chinese Academy of Sciences, Beijing 100085, China. E-mail: zhanghua7977@ 163.com \\ 2. Graduate University of Chinese Academy of Sciences, Beijing 100039, China
}

Received 25 February 2008; revised 10 April 2008; accepted 20 April 2008

\begin{abstract}
Dissolved organic matter (DOM) has been identified as precursor for disinfection by-products (DBPs) formation during chlorination. Recently, it has been demonstrated that the characteristics of DOM influence the DBPs formation mechanism. A study was, therefore, initiated to investigate the effects of DOM fractions on DBPs formation mechanism. In the chlorination process, organic acids are dominant precursors of total thihalomethanes (TTHM) because of the $v_{\mathrm{C}-\mathrm{O}}$ and unsaturated structures. Furthermore, the TTHM formation of organic acids was affected by $\mathrm{pH}$ more greatly. Based on the fluorescence spectroscopy analysis, DOM fractions contained several fluorescence substances. During chlorination, humic acid-like substances were found to exhibit high chlorine reactivity and hydrophobic organics decomposed to smaller molecules faster than hydrophilic organics even at lower chlorine dosages. Unlike hydrophobic fractions, hydrophilic organics showed no toxicity following chlorination, suggesting that the toxic structures in hydrophilic organics showed high chlorine reactivity during chlorination.
\end{abstract}

Key words: disinfection by-products; chlorination; characteristics; dissolved organic matter

\section{Introduction}

Chlorination has been considered to be a cost-effective approach for providing both primary disinfection to inactivate waterborne pathogens and for achieving the secondary disinfection by providing necessary residuals in the distribution system (Liu et al., 2006). However, many halogenated disinfection by-products (DBPs) have been identified during chlorination, such as thihalomethanes (THMs) and haloacetonitriles (HANs), which are associated with increased risk of cancer (Trevizo and Nirmalak, 1999; Monarca et al., 2004; Zha and Wang, 2005). Because dissolved organic matter (DOM) was regarded as the major precursor for DBPs, many researchers have focused their research on exploring the relationship between DOM and DBPs formation. Sirivedhin and Gray (2005) found a combination of aromatic and aliphatic structures including some substituted with nitrogen and chlorine to show a linear relationship with DBPs formation potential (DBPFP). Leenheer et al. (2001) demonstrated that phenol structures produced significant DBPs, whereas aromatic sulfonates and fulvic acids in reclaimed water contributed to minimal DBPs. It appears that the chemical characteristics of DOM influence the chlorine consumption and the formation of DBPs largely. Marhaba and Van (2000) isolated DOM from treatment plants and demonstrated that the hydrophilic acid fraction was the most reactive

\footnotetext{
* Corresponding author. E-mail: jhqu@rcees.ac.cn
}

precursor to the THM formation. However, limited research was conducted about the DBPs formation of DOM fractions under different conditions, and some of the DOM are toxic by themselves (Ono et al., 1996; Barker and Stuckey, 1999). Therefore, only measuring typical DBPs is insufficient to investigate the effect of DOM fractions on the safety of wastewater.

The aims of this study were to evaluate the chlorination mechanism of DOM fractions and to compare the toxicity produced by DOM fractions via chlorination. For these purposes, DOM from a conventional treatment plant was isolated using three resins into six fractions. DBPs formation was compared among different DOM fractions by varying conditions necessary for better performance, and the toxicity of DOM fractions was also investigated before and after chlorination.

\section{Materials and methods}

\subsection{Wastewater sampling and characterization}

Undisinfected reclaimed water samples were collected periodically at the sand-filtration site of secondary effluents from $G$ sewage treatment plant (GSTP), the largest STP in China with a treatment capacity of $1 \times 10^{6} \mathrm{~m}^{3} / \mathrm{d}$. After being filtered through $0.45 \mu \mathrm{m}$ cellulose membrane filters, the DOM samples were stored at $4{ }^{\circ} \mathrm{C}$ to minimize changes in the constituents. TOC concentrations of the effluent 
ranged from 7.2 to $8.2 \mathrm{mg} / \mathrm{L}$ and the $\mathrm{UV}_{254}$ to $\mathrm{DOC}$ ratio (SUVA) was in the range of 1.5-2.2 (abs.L)/(cm.g).

The freeze-drying DOM fractions was analyzed for the structural and chemical characteristics of DOM. KBr was mixed with the DOM powder at the ratio of 100 to 1 and the Fourtier transform infra-red (FT-IR) spectra of the mixture were obtained by scanning it with IR spectrometer (Thermo Nicolet 5700, USA).

\subsection{Chemicals and materials}

Solutions were prepared with ultra-pure water. A free chlorine $(\mathrm{HOCl})$ stock solution (about $5 \mathrm{~g} / \mathrm{L}$ ) was prepared from $7 \%$ sodium hypochlorite $(\mathrm{NaClO})$ and its concentration was measured prior to use according to DPD colorimetric method (EPA method 330.5). A $50 \mathrm{mmol} / \mathrm{L}$ sodium phosphate buffer solution was used to maintain solution at $\mathrm{pH} 7$.

Hexane used to extract DBPs was obtained from Fisher. THMs standard, i.e., chloroform $\left(\mathrm{CHCl}_{3}\right)$ and two HANs standards, i.e., dichloroacenitrile (DCAN) and trichloroacetonitrile (TCAN), were purchased from Aldrich (USA).

\subsection{Fractionation and collection of DOM fractions}

The fractionation of DOM was performed following the procedure modified from Leenheer (1981), Chefetz et al. (1998), and Imai et al. (2002).

A $0.45-\mu \mathrm{m}$ filtered reusewater was firstly pumped through a glass column of Amberlite XAD-8 resin (2060 mesh). Hydrophobic bases (HoB) were then desorbed from the resin with $0.1 \mathrm{~mol} / \mathrm{L} \mathrm{HCl}$. The sample effluent was acidified to $\mathrm{pH} 2$ with $6 \mathrm{~mol} / \mathrm{L} \mathrm{HCl}$ and cycled over three connected Amberlite XAD-8, Dowex Marathon MSC resin (20-50 mesh), and Duolite A7 (free base). The effluent from the connected three columns was hydrophilic neutrals (HiN). Hydrophobic acids (HoA), hydrophilic bases (HiB), and hydrophilic acids (HiA) were desorbed from XAD-8, Dowex Marathon MSC, and Duolite A7 with $0.1 \mathrm{~mol} / \mathrm{L}$ $\mathrm{NaOH}$, respectively. After HoA was desorbed, the XAD-8 resin was air-dried for about $12 \mathrm{~h}$ and was soxhletextracted with methanol to obtain hydrophobic neutrals (HoN). The excess methanol was removed by vacuumrotary evaporation at $40^{\circ} \mathrm{C}$.

\subsection{Analytical methods}

THMs and HANs analyses were conducted according to EPA method 551.1, using an Agilent 6890N Gas Chromatograph (USA) that was equipped with a fused silica capillary column (HP-5, $30 \mathrm{~m}, 320 \mu \mathrm{m} \times 0.25 \mu \mathrm{m}$ ) and a linearized electron capture detector (ECD). For experiments involving THMs and HANs, a temperature program was used wherein temperature was held at $35^{\circ} \mathrm{C}$ for $4 \mathrm{~min}$ and ramped to $60^{\circ} \mathrm{C}$ at $10^{\circ} \mathrm{C} / \mathrm{min}$.

Standard curves were obtained by extracting standards from the aqueous solutions and blank $(0 \mu \mathrm{g} / \mathrm{L}$ as DBPs $)$ of ultra-pure water was also included. In the study, DBPs of samples without chlorination were measured as the controls.

Fluorescence spectra were recorded on a fluorescence spectrophotometer (model F-4500, Hitachi, Japan). Threedimensional spectra were obtained by measuring the emission spectra in the range from 300 to $500 \mathrm{~nm}$ repeatedly at the excitation wavelengths from 230 to $400 \mathrm{~nm}$. Spectra were then converted into an excitation emission matrix (EEM). Blanks of ultra-pure water were included in the correction of inner filtering and Raman scattering of the fluorescence spectra.

\subsection{Chlorination procedures}

To compare the characteristics of DOM fractions, all samples were conditioned to similar TOC concentrations about $3 \mathrm{mg} / \mathrm{L}$. Buffer and chlorine were added into the water samples in sequence. Following incubation in dark at $20^{\circ} \mathrm{C}$ for $3 \mathrm{~d}$, the chlorination was quenched with sodium sulfite $\left(\mathrm{Na}_{2} \mathrm{SO}_{3}\right)$ and DBPs were analyzed by GC-ECD (Agilent, USA). In the experiments, to investigate $\mathrm{pH}$ effect, $2 \mathrm{~mol} / \mathrm{L} \mathrm{HCl}$ or $2 \mathrm{~mol} / \mathrm{L} \mathrm{NaOH}$ solution was used to adjust the $\mathrm{pH}$ of DOM samples. A series of chlorine dosages $\left(0-25 \mathrm{mg} / \mathrm{L}\right.$ as $\left.\mathrm{Cl}_{2}\right)$ was added into the samples to evaluate the effect of chlorine dosage.

All experiments were performed more than 3 times.

\subsection{Toxicity measurement}

Photobacterium bioassay method quantifies the decrease in light emission from the Photobacterium phosphoreum ( $P$. phosphoreum) bacterium as a result of exposure to pollutants for $15 \mathrm{~min}$ (Wang et al., 2007). The bacteria were provided as freeze-dried powder by the Institute of Soil Science, Chinese Academy Sciences, China. The luminescence intensity was determined by a test instrument (Model toxicity analyzer DXY-2, China).

\section{Results and discussion}

\subsection{DOM-fraction distribution}

Among the six DOM fractions, HoA dominated in reclaimed water, accounting for more than $34 \%$ of their DOM as TOC (Fig. 1). HiN was found to be the second most abundant fraction, constituting more than $20 \%$ of TOC. The HiA and HoN fractions accounted for about $15 \%$, respectively. In all fractions, organic bases, $\mathrm{HoB}$ and $\mathrm{HiB}$, constituted less than $10 \%$. In particular, the HoB fraction was low enough to be ignored.

Thus, DOM in reclaimed water from GSTP is primarily composed of organic acids and organic neutrals, which might serve as dominant DBPs precursors during chlorination.

\subsection{Characterization of DOM fractions}

\subsubsection{FT-IR analysis of DOM fractions}

The FT-IR spectra of DOM fractions are shown in Fig. 2. Interpretation of the absorption bands of DOM was done as described in the published works (Leenheer et al., 2001; Kim and Yu, 2005; Kanokkantapong et al., 2006).

The hydrophobic organics were similar in spectra with a distinctive adsorption band at $1400-1450 \mathrm{~cm}^{-1}$ referring to aliphatic structures, whereas the HoA fraction was found 


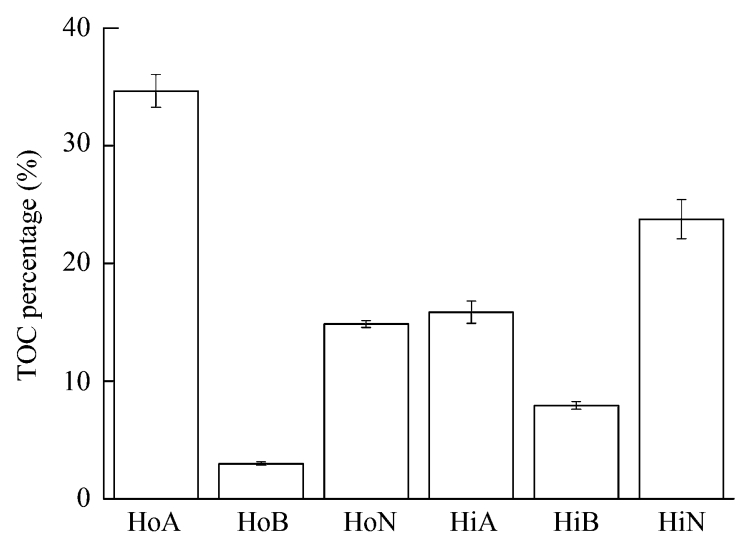

Fig. 1 DOC-fraction distribution. HoA: hydrophobic acids; HoB: hydrophobic bases; HoN: hydrophobic neutrals: HiA: hydrophilic acids; HiB: hydrophilic bases; HiN: hydrophilic neutrals.

to contain more $\mathrm{C}=\mathrm{C}$ or $\mathrm{C}=\mathrm{O}$ content at approximately $1600 \mathrm{~cm}^{-1}$. Compared with HoA and $\mathrm{HoN}$, the $\mathrm{HiA}$ and $\mathrm{HiN}$ fractions contained relatively high $\mathrm{C}-\mathrm{O}$ content at approximately $1100 \mathrm{~cm}^{-1}$.

\subsubsection{Fluorescence spectroscopy of DOM fractions}

In this study, DOM fractions showed different characteristics even at the same performed conditions. Thus, the investigation of the chemical structures of DOM fractions is useful to understand the difference.

Figure 3 illustrates the fluorescence spectroscopy of the four DOM fractions. Each fraction was mainly composed
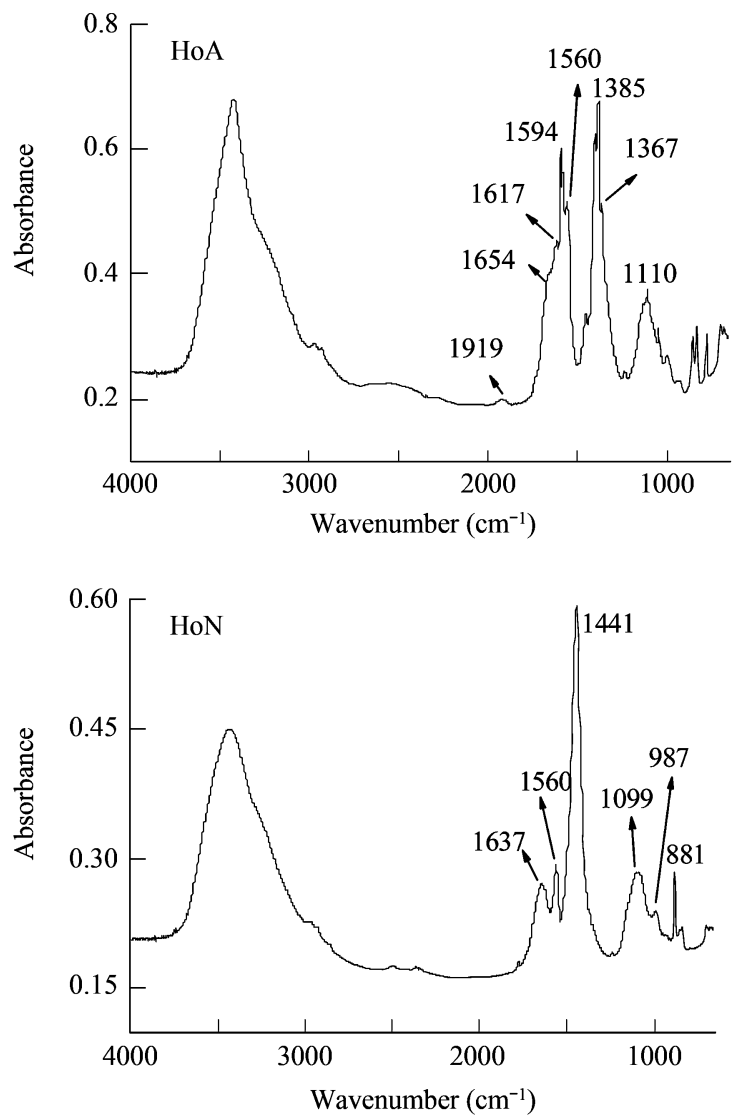

of humic acid-like and fulvic acid-like substances, but the organics were at different excitation and emission wavelength, and showed various intensities.

The corresponding fluorescence intensity of each substance source during chlorination was examined at various chlorine dosages, as shown in Fig. 4. In general, the fluorescence intensity of peak $\mathrm{V}$ attributable to humic acid-like decreased at a higher rate than those of other peaks, including peak III representing fulvic acid-like. Therefore, it can be concluded that humic acid-like displayed relatively high chlorine reactivity. Furthermore, the general fluorescence intensity of hydrophobic organics (HoA, HoN) decreased sharply at a chlorine dosage of $6.5 \mathrm{mg} / \mathrm{L}$ but varied little at higher chlorine dosage. However, the general fluorescence intensity of hydrophilic organics decreased at a relatively constant rate with the exception of peak III in the case of HiN. The result suggested that hydrophobic organics decomposed to smaller molecules faster than hydrophilic organics even at lower chlorine dosages.

\subsection{Factors affecting the total THMs and TCAN forma- tion of DOM fractions}

\subsubsection{Reaction time effect}

When a chlorine dosage of $20 \mathrm{mg} / \mathrm{L}$ was applied to the four DOM fractions buffered at $\mathrm{pH} 7$, the formation of total THMs (TTHM) and HCANs was investigated during $72 \mathrm{~h}$ chlorination (Fig. 5). In all cases, TTHM formation monotonously increased with increase reaction time and the slopes (increments of TTHM formation per unit time)
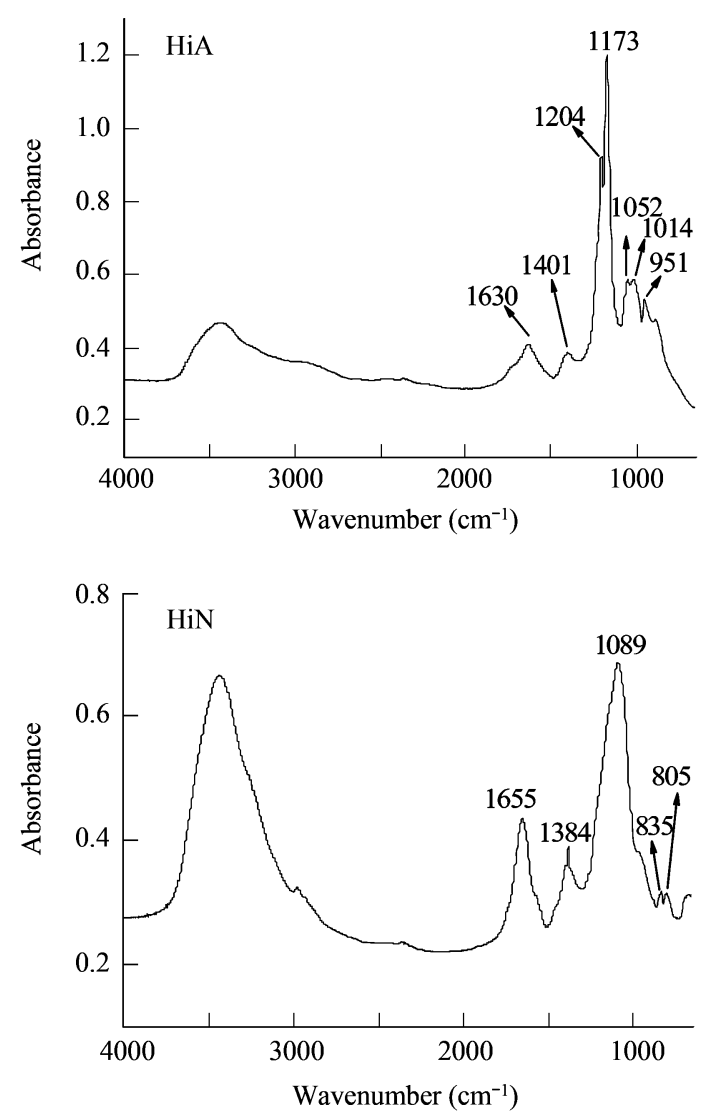

Fig. 2 FT-IR specta of DOM fractions. 

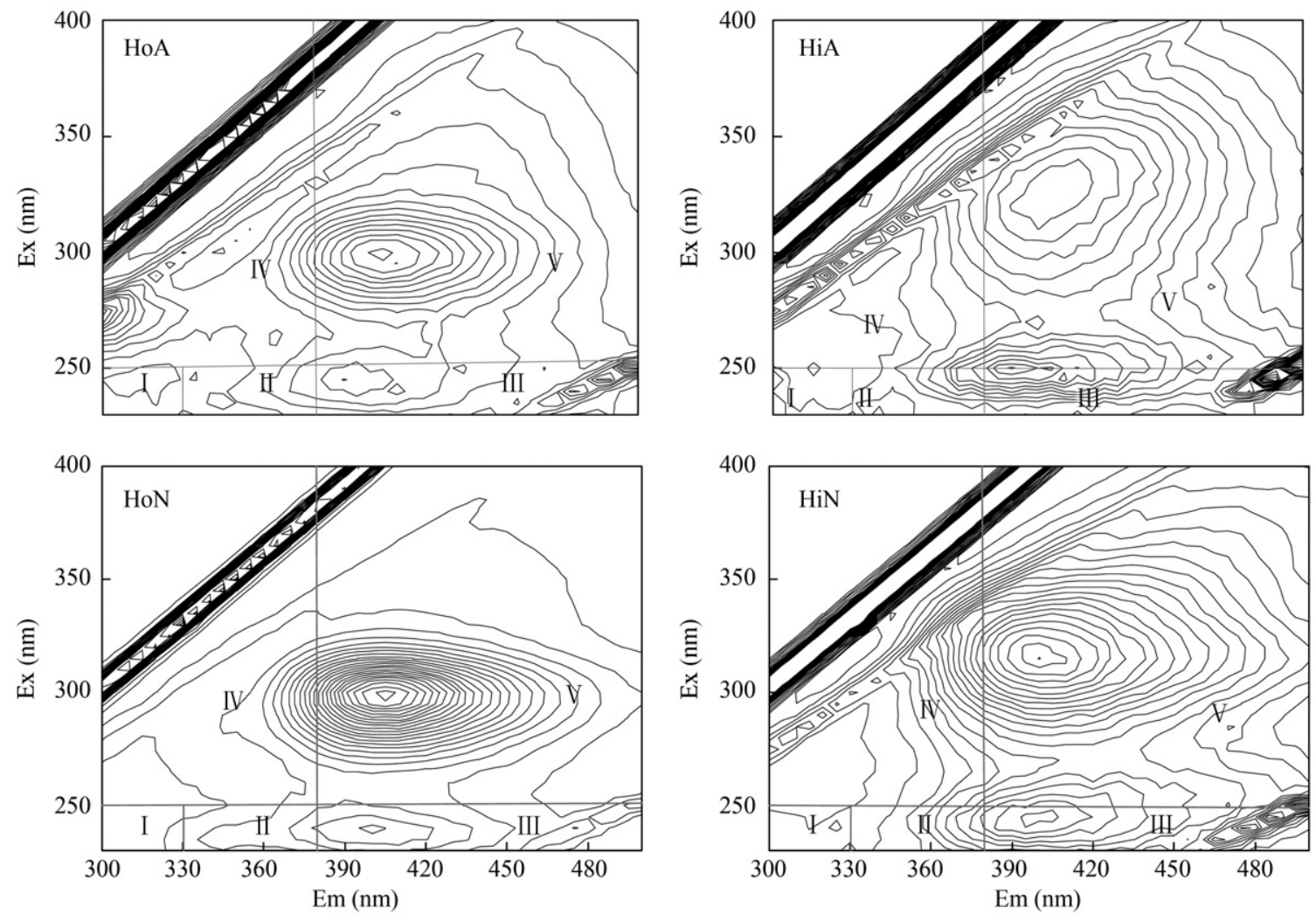

Fig. 3 Fluorescence spectroscopy of DOM fractions. I: aromatic protein I; II: aromatic protein II; III: fulvic acid-like products; IV: soluble microbial products; V: humic acid-like products. Ex: excitation wavelength; Em: emission wavelength.
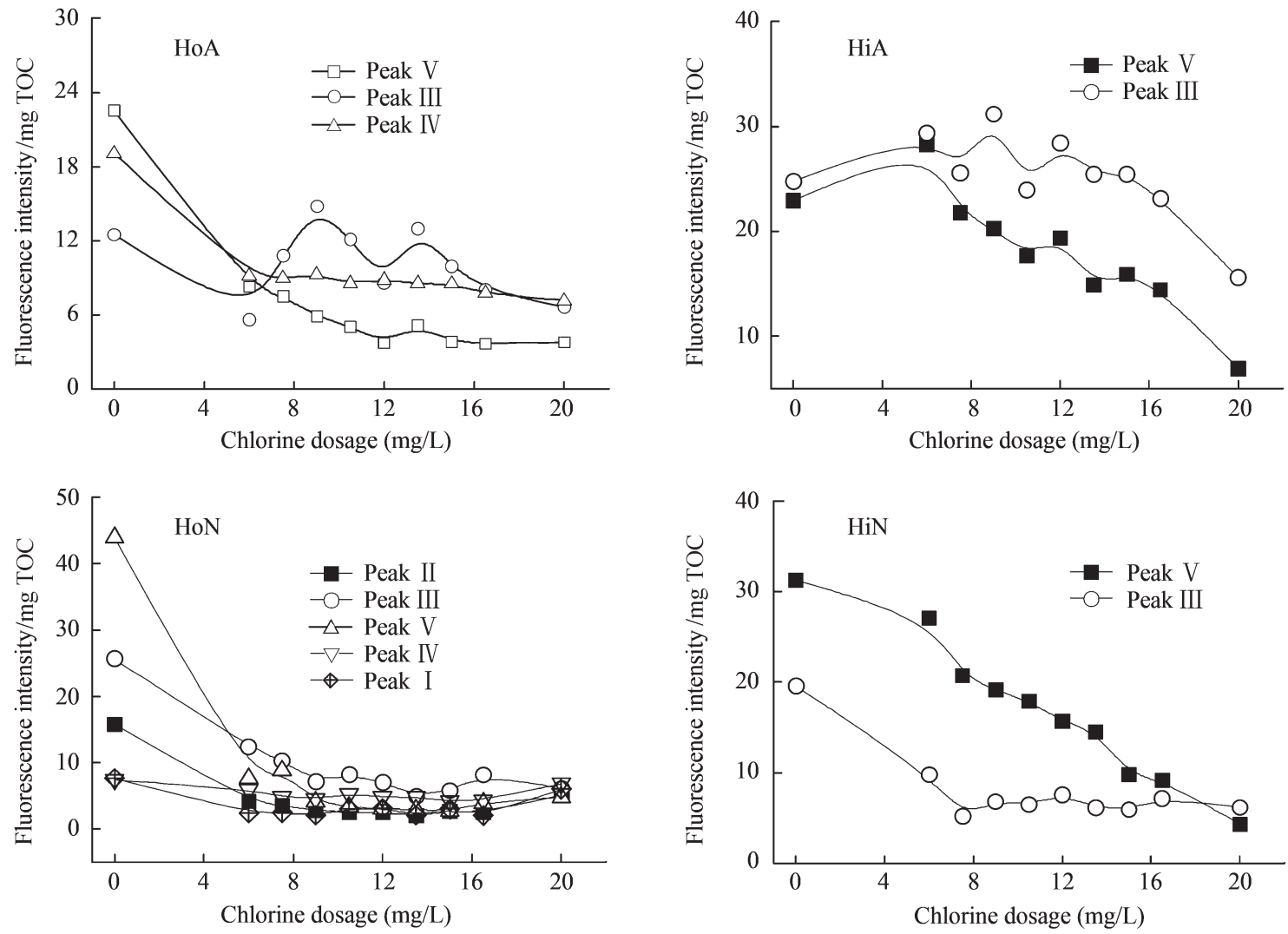

Fig. 4 Effect of chlorine dosage on the fluorescence intensity of DOM fractions. 

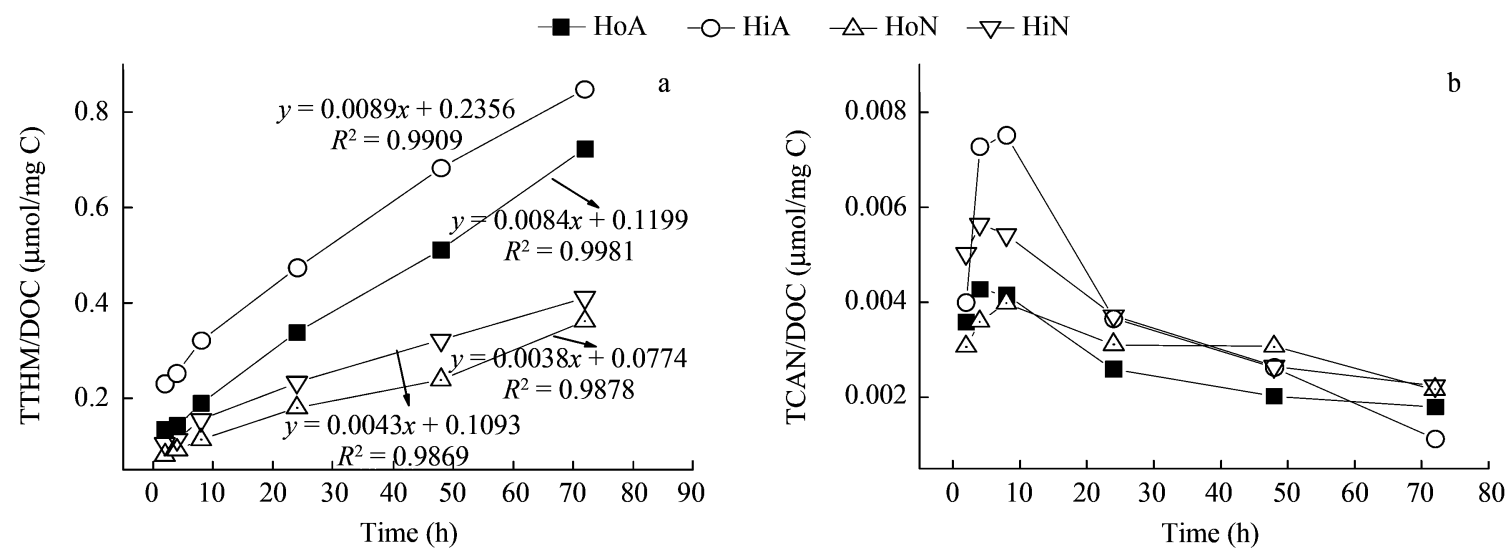

Fig. 5 Effect of reaction time on the formation of total THMs (TTHM) and trichloroacetonitrile (TCAN) of DOM fractions. Experimental conditions: $\mathrm{pH} 7.0$; initial $\mathrm{Cl}_{2}$ concentration $20 \mathrm{mg} / \mathrm{L}$; incubation temperature $20^{\circ} \mathrm{C}$.
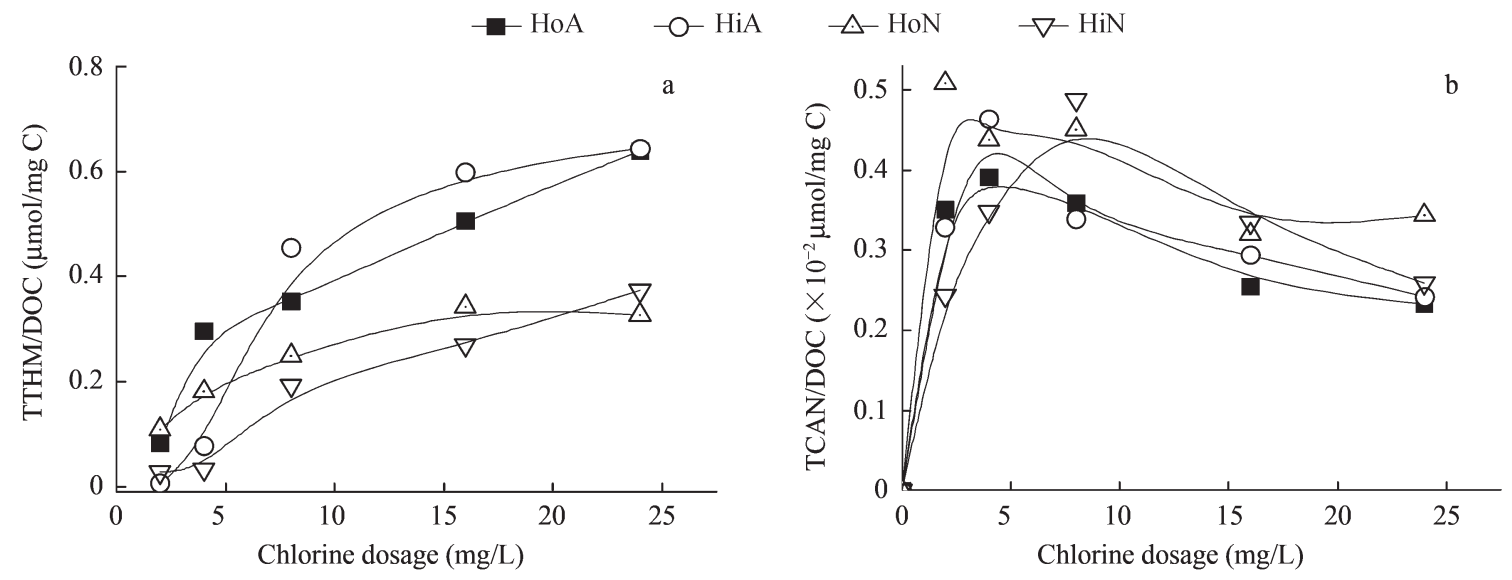

Fig. 6 Effect of chlorine dosage on the formation of total THMs and TCAN of DOM fractions. Experimental conditions: pH 7.0; reaction time $3 \mathrm{~d}$; incubation temperature $20^{\circ} \mathrm{C}$.

of HoA, HiA, HoN, and HiN were 0.0084, 0.0089, 0.0038, and $0.0043 \mu \mathrm{mol} /(\mathrm{mg} \cdot \mathrm{h})$, respectively (Fig. 5a). Clearly, the TTHM formation of HiA and HoA increased much. Furthermore, the TTHM formation potential decreased as the following sequence: $\mathrm{HiA}, \mathrm{HoA}, \mathrm{HiN}$, and $\mathrm{HoN}$. These findings suggest that organic acids are dominant precursors of TTHM; however, whether in organic acids or organic neutrals, hydrophilic organics predominated over the corresponding fraction.

The results can be partially explained by the chemical structures of DOM fractions. Compared with HoA and $\mathrm{HoN}$, the HiA and HiN fractions contained relatively high $\mathrm{C}-\mathrm{O}$ content at about $1100 \mathrm{~cm}^{-1}$, thus leading to higher TTHM formation potential than their corresponding fraction. In addition to chlorine substitution, chlorine attack on unsaturated structures plays a substantial role in the formation of $\mathrm{CHCl}_{2}-\mathrm{CO}-\mathrm{R}$ or $\mathrm{CCl}_{3}-\mathrm{CO}-\mathrm{R}$. Of the four fractions, HoA was found to contain more $\mathrm{C}=\mathrm{C}$ or $\mathrm{C}=\mathrm{O}$ content at approximately $1600 \mathrm{~cm}^{-1}$, which partially contributed to the formation of TTHM. Yang et al. (2007) demonstrated that chlorination of fulvic acids leads to the formation of intermediate by-products, such as $\mathrm{CHCl}_{2}-$ $\mathrm{CO}-\mathrm{R}$ or $\mathrm{CCl}_{3}-\mathrm{CO}-\mathrm{R}$, which can be hydrolyzed to form chloroform. Therefore, organics containing $\mathrm{C}-\mathrm{O}$ groups might form TTHM more easily.
DCAN was below the detection limit throughout the test. In all cases, the concentration of TCAN reached its maximum during 5-10 h before undergoing hydrolysis at longer reaction time (Fig. 5b), suggesting that TCAN is the intermediate product in forming other DBPs. The result agreed with the study by Yang et al. (2007). As known, TCAN can be formed from chlorine substitution of $\mathrm{N}$ containing structures or by chloramination (Yang et al., 2005). In this study, $\mathrm{NH}_{3}-\mathrm{N}$ was absent in the four DOM fractions; however, the reclaimed-water that contained 1 to $2 \mathrm{mg} / \mathrm{L} \mathrm{NH}-\mathrm{N}$ produced TCAN 3 to 4 times higher than DOM fractions (the data was not shown). The findings suggest that controlling dissolved ammonia can be a good strategy to prevent the enhanced yields of TCAN.

\subsubsection{Chlorine dosage effect}

The 3-day chlorination test was examined after dosing with different concentrations of sodium hypochlorite (as $\mathrm{mg} / \mathrm{L} \mathrm{Cl}_{2}$ ) in DOM fractions buffered at $\mathrm{pH}$ 7. The TTHM formation of all fractions increased with higher chlorine dosage, but the progressiveness of increase was different (Fig. 6a). Organic acids showed relatively high slopes compared to organic neutrals, indicating that TTHM precursors in organic acids possessed relatively high chlorine reactivity. With chlorine dosage higher than $10 \mathrm{mg} / \mathrm{L}$, 
the HiA fraction formed the highest TTHM; however, its TTHM concentration increased more gently than that of the HoA fraction. It can be explained by the high content of unsaturated bonds in the HoA fraction, because it was possible for TTHM to form more with high chlorine dosage to attack the $\mathrm{C}=\mathrm{C}$ or $\mathrm{C}=\mathrm{O}$ groups.

There was a distinctive increasing tendency for the formation of TCAN with the chlorine dosage increasing (Fig. 6b). However, the concentration of TCAN achieved the greatest yields at a chlorine dosage of about $5 \mathrm{mg} / \mathrm{L}$ before decreasing with the increase of chlorine dosage. The exception was HoN with the maximum TCAN formation occurring at the chlorine dosage of $10 \mathrm{mg} / \mathrm{L}$.

Because of the absence of $\mathrm{NH}_{3}-\mathrm{N}$ in DOM fractions, the formation of TCAN depends on N-containing structures. Furthermore, the apparent intermediate reactant behavior of TCAN indicated that the chlorine to nitrogen ratios greatly affected the formation of TCAN. Although the results suggest that excessive chlorine will decompose TCAN, we can not detemine the influence of complex chemical structures on TCAN formation. A study focused on the mechanisms of DBPs formation is still in progress.

\subsection{3 pH effect}

The effect of $\mathrm{pH}$ on the TTHM formation of wastewater or surface water has been well documented in the published works (Monarca et al., 2004). Above pH 7, the alkaline conditions have a positive effect on the formation of TTHM. A similar trend was observed when DOM fractions (buffered at pH 5, 7 and 9) were chlorinated for 3 $\mathrm{d}$ with different chlorine dosages (Fig. 7).

In all cases, the concentration of TTHM achieved the minimum at $\mathrm{pH} 5$ and varied little with increasing chlorine dosage. It might be because of the lack of hydrolysis of intermediates in the formation of TTHM although chlorine species at $\mathrm{pH} 5$ possess relatively high oxidation potential (Heller-Grossman et al., 1999). However, the TTHM formation showed a distinctive and positive correlation with chlorine dosage at pH 7 and 9 (Table 1). Furthermore, the higher slopes at $\mathrm{pH} 9$ indicated that TTHM underwent base-catalyzed composition and formed more easily at alkaline conditions.

Of the four DOM fractions, organic acids showed higher slopes than organic neutrals. In particular at $\mathrm{pH} \mathrm{9,} \mathrm{the}$ slopes of HoA and HiA were 0.1241 and 0.1451 ; which
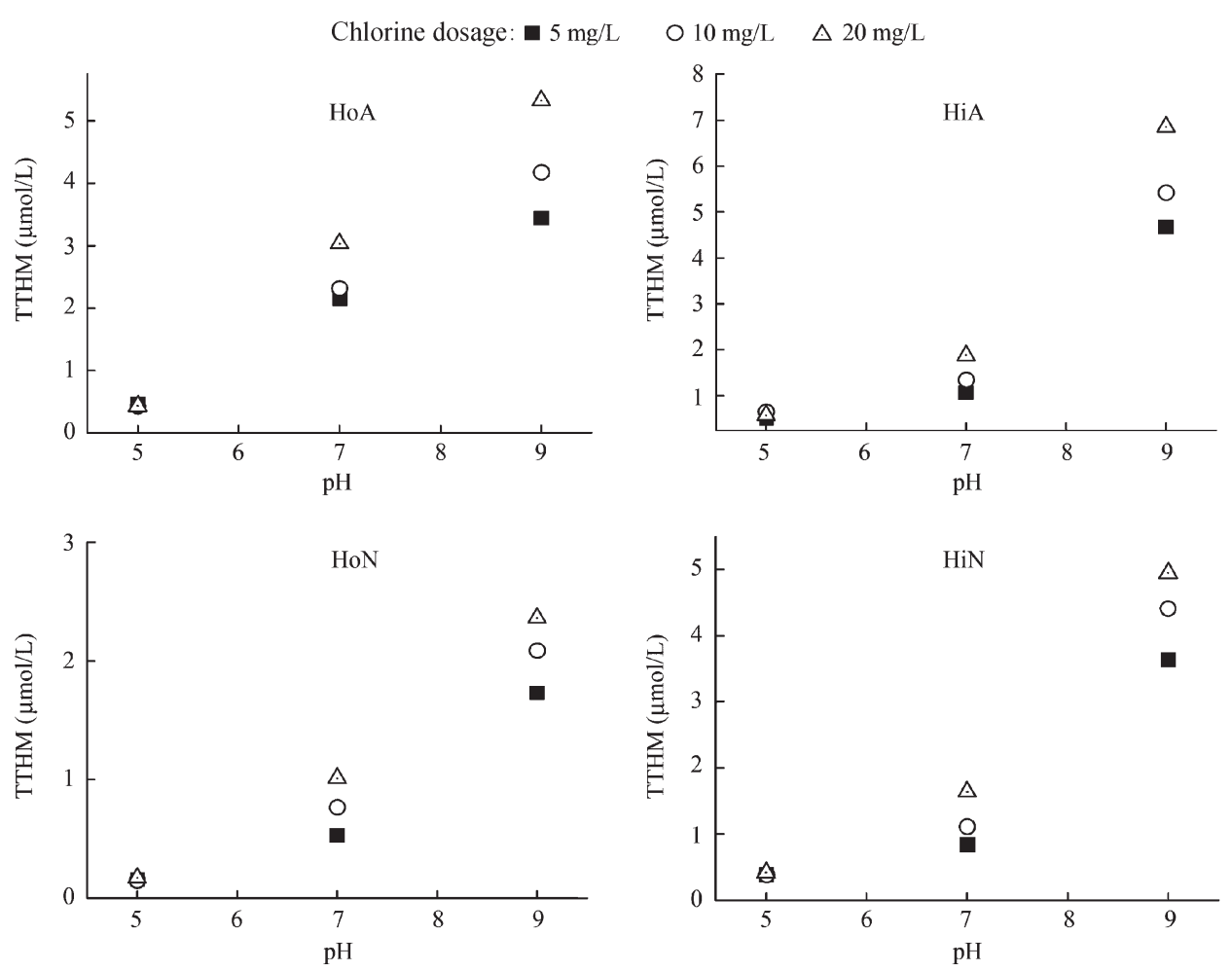

Fig. 7 Effect of $\mathrm{pH}$ on the formation of TTHM of DOM fractions. Experimental conditions: reaction time $3 \mathrm{~d}$; incubation temperature $20^{\circ} \mathrm{C}$.

Table 1 Linear relationship of TTHM formation and chlorine dosage at $\mathrm{pHs}$

\begin{tabular}{llll}
\hline DOM fractions & $\mathrm{pH} 5$ & $\mathrm{pH}$ & $\mathrm{pH} \mathrm{9}$ \\
\hline $\mathrm{HoA}$ & $\mathrm{NA}$ & $y=0.0605 x+1.7907, R^{2}=0.98$ & $y=0.1241 x+2.8677, R^{2}=1.0$ \\
$\mathrm{HiA}$ & $\mathrm{NA}$ & $y=0.0538 x+0.8095, R^{2}=1.0$ & $y=0.1451 x+3.9631, R^{2}=1.0$ \\
$\mathrm{HoN}$ & $\mathrm{NA}$ & $y=0.031 x+0.4096, R^{2}=0.97$ & $y=0.04 x+1.5958, R^{2}=0.93$ \\
$\mathrm{HiN}$ & $\mathrm{NA}$ & $y=0.053 x+0.5789, R^{2}=1.0$ & $y=0.0829 x+3.3647, R^{2}=0.92$ \\
\hline
\end{tabular}

NA: not available. 

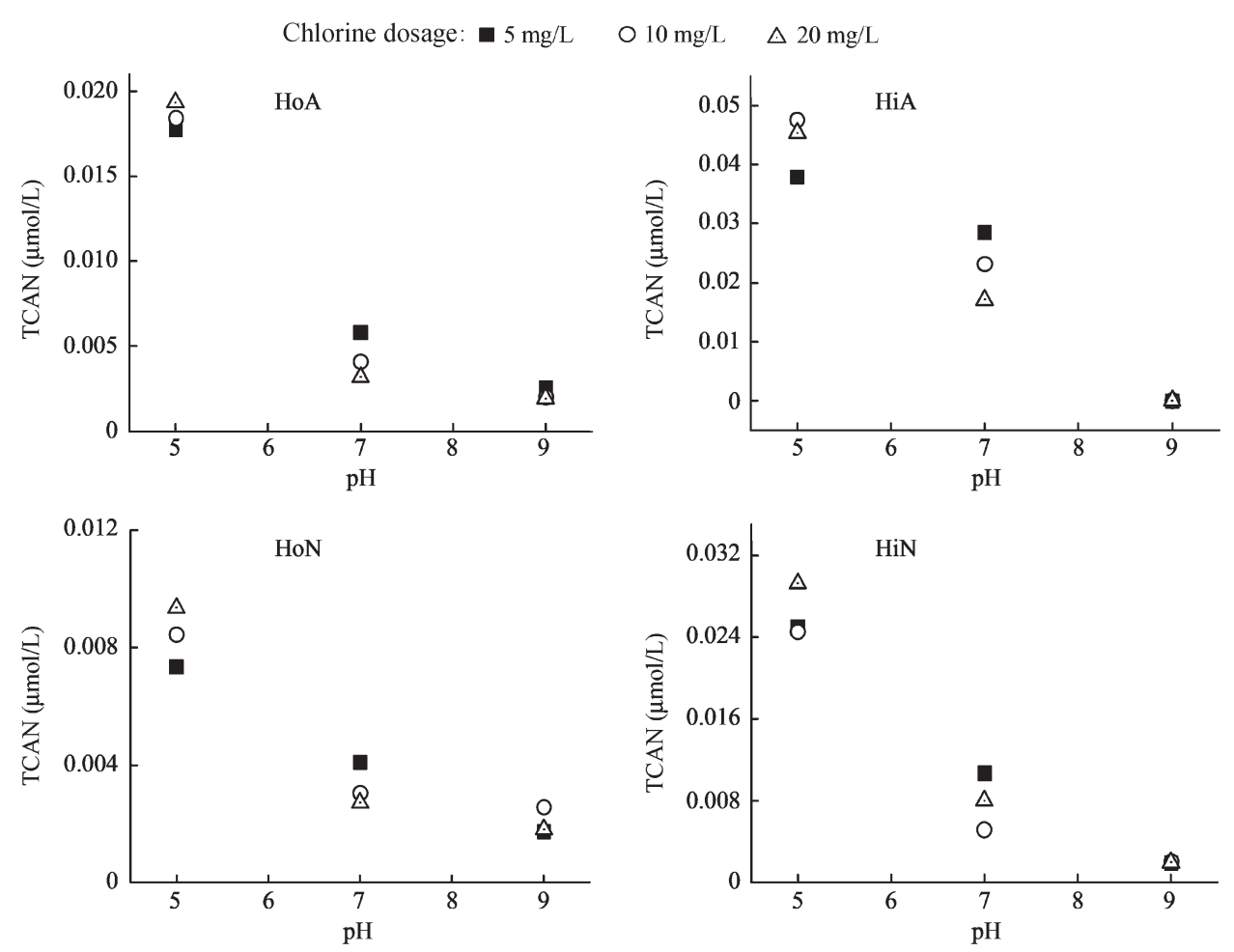

Fig. 8 Effect of $\mathrm{pH}$ on the formation of TCAN of DOM fractions. Experimental conditions: reaction time $3 \mathrm{~d}$; incubation temperature $20^{\circ} \mathrm{C}$.

are about three times the slope of HoN and one more time of HiN, respectively. The findings are consistent with the result of chlorine dosage dependence test. Furthermore, the slope ratios (slope at $\mathrm{pH} 9$ to slope at $\mathrm{pH} 7$ ) of $\mathrm{HoA}$, HiA, HoN, and HiN were 2.05, 2.70, 1.29, and 1.56, respectively. Thus, it can be concluded that organic acids were affected by $\mathrm{pH}$ more greatly, in particular the HiA fraction.

The TCAN formation decreased with the increase of $\mathrm{pH}$ (Fig. 8). As shown in this study, TCAN formation achieved the maximum at $\mathrm{pH} 5$ but declined at a great rate with the increase of $\mathrm{pH}$. Unlike TTHM, TCAN might undergo base-catalyzed decomposition and $\mathrm{pH}$ affects its stability largely. At acidic conditions, the TCAN formation was found to increase with chlorine dosages increasing. However, at $\mathrm{pH} \mathrm{7,} \mathrm{the} \mathrm{maximum} \mathrm{TCAN} \mathrm{formation} \mathrm{occurred} \mathrm{at}$ the least chlorine dosage.

Based on above discussion, the general trend of TCAN formation can be explained as follows. $\mathrm{pH}$ affects DBPs formation through deprotonation of the hypochlorous acid (HOCl) (Heller-Grossman et al., 1999). The dissociation constant $\left(K_{\mathrm{a}}\right)$ of $\mathrm{HOCl}$ is $3.2 \times 10^{-8} \mathrm{~L} / \mathrm{mol}$. Thus, at $\mathrm{pH}$ $7.5, C_{\mathrm{HOCl}} \approx C_{\mathrm{OCl}^{-}}(50 \%$ protonated $)$ and the protonation declines at high $\mathrm{pH}$. Therefore, the decomposition of TCAN is base-catalyzed and enhanced with the increase in $\mathrm{pH}$. Yang et al. (2007) demonstrated that HANs were not stable in free chlorine. However, in this study, TCAN formation increased with higher chlorine dosages at $\mathrm{pH} 5$ although it decreased at $\mathrm{pH}$ 7. Thus, it is hypothesized that the TCAN decomposition in the presence of chlorine is attributable to the presence of $\mathrm{OCl}^{-}$and not its protonation form.

\subsection{Photobacterium bioassay test of DOM fractions be- fore and after chlorination}

To assess the toxic effect caused by DOM fractions and chlorination, Photobacterium bioassay was used in this study. The higher the luminescence on the control basis is, the lower the toxic effect should be. Fig. 9 presents a summary of toxicity evaluation on DOM fractions before and after chlorination.

Clearly, hydrophilic organics (HiA, HiN) showed higher toxic effect than hydrophobic fractions (HoA, HoN) before chlorination. However, it is important to note that the toxicity of hydrophilic organics was even lower after chlorination. The results are quite contrary to the toxicity changes of hydrophobic organics and reclaimed water, in which chlorination enhanced toxic effect (the data of reclaimed-water was not shown). Thus, it can be concluded that hydrophilic organics are toxic to Photobacterium, but

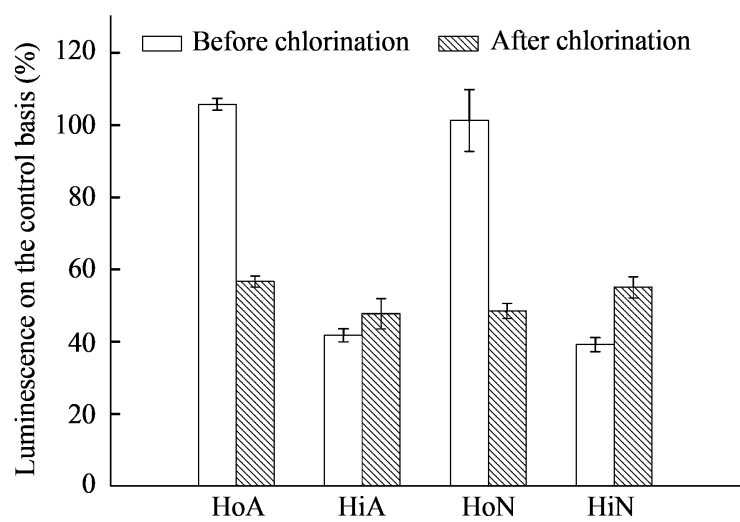

Fig. 9 Toxicity of DOM fractions before and after chlorination. 
during chlorination, the toxic structures were conformed. Therefore, the toxic structures in hydrophilic organics show high chlorine reactivity.

\section{Conclusions}

DOM from GSTP mainly comprised of organic acids and organic neutrals. In the chlorination process, organic acids were dominant precursors of TTHM because of the $v_{\mathrm{C}-\mathrm{O}}$ and unsaturated structures. Furthermore, TTHM underwent base-catalyzed composition. Organic acids, in particular, the HiA fraction, were affected by $\mathrm{pH}$ more greatly. Unlike TTHM, TCAN underwent base-catalyzed decomposition and showed apparent intermediate-reactant behavior.

In view of fluorescence spectroscopy analysis, humiclike were found to exhibit high chlorine reactivity during chlorination.

Hydrophilic organics showed higher toxic effect than hydrophobic fractions before chlorination. However, the toxicity of hydrophilic fractions was reduced after chlorination, suggesting that the toxic structures in hydrophilic organics showed high chlorine reactivity.

\section{Acknowledgments}

This work was supported by the National Natural Science Foundation of China (No. 50538090), the Funds for Creative Research Groups of China (No. 50621804) and the High-Tech Research and Development Program (863) of China (No. 2007AA06Z338).

\section{References}

Barker D J, Stuckey D C, 1999. A review of soluble microbial products (SMP) in wastewater treatment systems. Water Research, 33(14): 3063-3082.

Blatchley III E R, Margetas D, Duggirala R, 2003. Copper catalysis in chloroform formation during water chlorination. Water Research, 37(18): 4385-4394.

Chefetz B, Hatcher P G, Hadar Y, 1998. Characterization of dissolved organic matter extracted from composted municipal solid waste. Soil Science Society of America Journal, 62(2): 326-332.

Heller-Grossman L, Idin A, Limoni-Relis B, Rebhun M, 1999. Formation of cyanogen bromide and other volatile DBPs in the disinfection of bromide-rich lake water. Environmental Science and Technology, 33(6): 932-937.

Imai A, Fukushima T, Matsushige K, 2002. Characterization of dissolved organic matter in effluents from wastewater treatment plants. Water Research, 36(4): 859-870.

Kanokkantapong V, Marhaba T F, Pavasant P, 2006. Characterization of haloacetic acid precursors in source water. Journal of Environmental Management, 80(3): 214-221.

Kim H C, Yu M J, 2005. Characterization of natural organic matter in conventional water treatment processes for selection of treatment processes focused on DBPs control. Water Research, 39(19): 4779-4789.

Leenheer J A, 1981. Comprehensive approach to preparative isolation and fractionation of dissolved organic carbon from natural waters and wastewaters. Environmental Science and Technology, 15(5): 578-587.

Leenheer J A, Rostas C, Barber L, 2001. Nature and chlorine reactivity of organic constituents from reclaimed water in groundwater, Los Angeles County, California. Environmental Science and Technology, 35(19): 3869-3876.

Liu W, Cheung L M, Yang X, Shang C, 2006. THM, HAA and $\mathrm{CNCl}$ formation from UV irradiation and chlor(am)ination of selected organic waters. Water Research, 40(10): 43854394.

Marhaba T F, Van D, 2000. The variation of mass and disinfection by-product formation potential of dissolved organic matter fractions along a conventional surface water treatment plant. Journal of Hazardous Materials, 74(3): 133-147.

Monarca S, Zani C, Richardson S D, 2004. A new approach to evaluating the toxicity and genotoxicity of disinfected drinking water. Water Research, 38(17): 3809-3819.

Ono Y, Somiya I, Kawaguchi T, Mohri S, 1996. Evaluation of toxic substances in effluents from a wastewater treatment plant. Desalination, 106(1-3): 255-261.

Sirivedhin T, Gray K A, 2005. 2. Comparison of the disinfection by-product formation potentials between a wastewater effluent and surface waters. Water Research, 39(6): 1025-1036.

Trevizo C, Nirmalak H N, 1999. Prediction of microbial toxicity of industrial organic chemicals. Water Science and Technology, 39(10-11): 63-69.

Wang L S, Wei D B, Wei J, Hu H Y, 2007. Screening and estimating of toxicity formation with Photobacterium bioassay during chlorine disinfection of wastewater. Journal of Hazardous Materials, 141(1): 289-294.

Yang X, Shang C, Huang J C, 2005. DBP formation in breakpoint chlorination of wastewater. Water Research, 39(19): 47554767.

Yang X, Shang C, Westerhoff P, 2007. Factors affecting formation of haloacetonitriles, haloketones, chloropicrin and cyanogen halides during chloramination. Water Research, 41(6): 1193-1200.

Zha J M, Wang Z J, 2005. Assessing technological feasibility for wastewater reclamation based on early life stage toxicity of Japanese medaka (Oryzias latipes). Agriculture, Ecosystems and Environment, 107(2-3): 187-198. 